\title{
Voltage-Gated Sodium Channels Are Targets for Toxins from the Venom of the Spider Heriaeus melloteei ${ }^{1}$
}

\author{
A. S. Nikolsky ${ }^{a}$, B. Billen ${ }^{b}$, A. A. Vassilevski ${ }^{a}$, S. Yu. Filkin ${ }^{a}$, J. Tytgat ${ }^{b}$, E. V. Grishin ${ }^{a}$ \\ ${ }^{a}$ Shemyakin and Ovchinnikov Institute of Bioorganic Chemistry, Russian Academy of Sciences, \\ ul. Miklukho-Maklaya, 16/10, Moscow,117997 Russia; e-mail: avas@ibch.ru. \\ ${ }^{b}$ Laboratory of Toxicology, University of Leuven, Campus Gasthuisberg, \\ O\&N 2, P.O. Box 922, Herestraat 49, 3000 Leuven, Belgium
}

Received March 27, 2009

\begin{abstract}
Three novel peptides were isolated from the venom of the spider Heriaeus melloteei (Thomisidae) and characterized. The peptides named $\mathrm{Hm}-1,2$ and 3 blocked voltage-gated $\mathrm{Na}^{+}$channels at concentrations in the order of $100 \mathrm{nM}$. Activity of the purified peptides was investigated in $\mathrm{Na}^{+}$channel isoforms of mammals and insects. Hm-1 and 2 appeared to act as pore blockers, whereas Hm-3 modulated the channel activation process. The toxins described exhibit minor similarity with other known peptides and may therefore constitute new groups of $\mathrm{Na} \cong+$ channel ligands.
\end{abstract}

Key words: spider venom, voltage-gated sodium channels, toxin, peptide structure, blocker, modulator DOI: $10.1134 / \mathrm{S} 1990747809030027$

Voltage-gated sodium $\left(\mathrm{Na}^{+}\right)$channels play a crucial role in processes of propagating action potentials in neuronal tissues and homeostasis maintenance [1]. Structure and function studies of these membrane transport systems play an important role in modern neurobiology. Indispensable tools for such studies are natural toxins specifically acting on these targets. In the 1970s-1980s, G.N. Mozhaeva with colleagues were exploring action mechanisms of some natural toxins, including plant alkaloid aconitine, steroid batrachotoxin (BTX) from the skin of Colombian frog, and polypeptide toxins from the scorpion Buthus eupeus, on various characteristics of $\mathrm{Na}^{+}$channels: conductance, selectivity, kinetics of activation and inactivation [2-7]. Since then, due to the emergence of new techniques and equipment, an arsenal of tools has been significantly enhanced, allowing detailed examination of pharmacology, structure-functional characteristics and physiological role of many types of $\mathrm{Na}^{+}$channels [8-12].

The spatial organization of $\mathrm{Na}^{+}$channels is still unclear. The $\alpha$-subunit $(\sim 260 \mathrm{kDa})$ is the major channel component and represents an integral membrane protein containing all the functional elements of the channel: the ion-conducting pore, selectivity filter, voltage sensor, and different ligand binding sites. $\beta$-Subunits, for instance $\beta 1(\sim 38 \mathrm{kDa})$ and $\beta 2(\sim 33 \mathrm{kDa})$, are additional and play a modulatory role. The channel's $\alpha$ subunit consists of four homologous domains (I-IV), each domain in turn consists of six transmembrane segments (S1-S6). The channel pore is formed between

\footnotetext{
${ }^{1}$ The article was translated by the authors.
}

segments S5 and S6 of the four domains, which also contain the selectivity filter. It was found that the S4 segments play the role of the voltage sensor [13-15].

Using electrophysiological, biochemical, and molecular biological techniques at least nine isoforms of the voltage-gated $\mathrm{Na}^{+}$channel $\alpha$-subunit $\left(\mathrm{Na}_{\mathrm{v}} 1.1-\right.$ $\mathrm{Na}_{\mathrm{v}}$ 1.9) have been found in mammals and eight genes have been successfully expressed in a heterological system [15]. Currently, at least seven different ligandbinding sites (so-called receptor sites) of natural toxins and some pharmacological agents have been described in $\mathrm{Na}^{+}$channels. Two groups of toxins interact with receptor site 1: heterocyclic tetrodotoxin (TTX) and saxitoxin, as well as peptidic $\mu$-conotoxins from venoms of marine snails of the genus Conus. In accordance with the sensitivity to TTX, $\mathrm{Na}^{+}$channel isoforms are allocated to the TTX-sensitive (TTX-S) and TTX-resistant (TTX-R: $\mathrm{Na}_{\mathrm{v}} 1.5, \mathrm{Na}_{\mathrm{v}} 1.8$, and $\mathrm{Na}_{\mathrm{v}} 1.9$ ). Toxins acting on site 1 do not alter the kinetics of the channels or their current-voltage relationships and influence only the ion conductivity, physically occluding the ion current, and thus are considered pore blockers. Other ligands modulate the activation and/or inactivation of the channels. Lipophylic grayanotoxin and alkaloids like veratridine, aconitine, and BTX bind to receptor site 2 and inhibit inactivation as well as shift the voltage-dependence of activation of the channels. Receptor site 3 is a target for a number of molecules: scorpion $\alpha-$ toxins, some marine shellfish, cone snail and spider toxins, all of which slow down or block the process of inactivation of the channels. Scorpion $\beta$-toxins as well as some spider toxins interact with site 4 . These sub- 
stances shift the threshold of the activation of the channels to the more negative membrane potentials. Brevetoxin and ciguatoxin potentiate $\mathrm{Na}^{+}$channels by targeting site 5; they shift the activation potential of the channels and also block the process of inactivation. $\delta$ Conotoxins interact with the site 6 and slow down the inactivation of the channels. Site 7 was identified as the target of liposoluble pyrethroid insecticides and DDT, also inhibiting the channel inactivation [16-18]. In contrast to the wide variety of modulators, the set of the known $\mathrm{Na}^{+}$channel pore blockers is limited and includes only a few examples, among them certain spider toxins: hainantoxins I and III-V from Haplopelma hainanum [19-21], huwentoxins I and IV from Haplopelma schmidti [22-24], Tx 1 from Phoneutria nigriventer [25, 26], and Hm-1 and 2 from Heriaeus melloteei [27].

Despite certain success, structure and physiological role of many types of voltage-gated $\mathrm{Na}^{+}$channels remain unresolved; therefore, the problem of obtaining new modulators of their activity is highly relevant. By example of this work, we would like to show how using an arsenal of modern techniques, search of the new $\mathrm{Na}^{+}$ channel blockers is performed.

\section{EXPERIMENTAL}

Biological material. Spider venoms were provided by A. Feodorov (Fauna Labs; Almaty, Kazakhstan). In every case, venoms were collected form 10-20 adult species of both genders by electrostimulation, frozen immediately and lyophilized.

Venom separation. Crude venom of the spider Heriaeus melloteei was separated by reverse-phase high-performance liquid chromatography (RP-HPLC) on a Jupiter $\mathrm{C}_{5}$ column $(4.6 \times 150 \mathrm{~mm}$, Phenomenex, USA) using a 60 -min linear gradient of acetonitrile $(0-60 \%, v / v)$ in aqueous trifluoroacetic acid (TFA; $0.1 \%, \mathrm{v} / \mathrm{v}$ ) at a flow rate of $1 \mathrm{ml} / \mathrm{min}$. Detection of eluate absorbance was performed at 210 and $280 \mathrm{~nm}$. Fractions obtained were lyophilized and then tested. Active fractions were exposed to a second step HPLC on a Luna $\mathrm{C}_{8}$ column $(4.6 \times 150 \mathrm{~mm}$, Phenomenex, USA) using a $60-\mathrm{min}$ linear gradient $(30-70 \%$ or $10-50 \%)$ of elution solvent $(50 \%$ acetonitrile, v/v, $20 \%$ isopropanol, v/v) in $0.1 \% \mathrm{TFA}$ at a flow rate of $1 \mathrm{ml} / \mathrm{min}$. The final stage of the active molecules purification was performed on a Luna $\mathrm{C}_{18}$ column $(2 \times 150 \mathrm{~mm}$, Phenomenex, USA) using an 80-min linear gradient of acetonitrile $(10-50 \%, \mathrm{v} / \mathrm{v})$ in $0.1 \% \mathrm{TFA}$ at a flow rate of $0.1 \mathrm{ml} / \mathrm{min}$.

Insect toxicity assays. Venom fractions obtained were analyzed for toxicity using Sarcophaga carnaria larvae (mass of $\sim 70 \mathrm{mg}$ ). Lyophilized substances were dissolved in physiological saline $(140 \mathrm{mM} \mathrm{NaCl}, 5 \mathrm{mM}$ $\mathrm{KCl}, 5 \mathrm{mM} \mathrm{CaCl}_{2}, 1 \mathrm{mM} \mathrm{MgCl}, 4 \mathrm{mM} \mathrm{NaHCO}_{3}$ and $5 \mathrm{mM}$ HEPES, pH 7.2). Samples were injected using a microsyringe (Hamilton, USA) into the forth segment of larvae. The experiment was carried out in triplicate; pure saline injection served as control. Development of paralytic and lethal effects was monitored for $24 \mathrm{~h}$.

Electrophysiological studies. For different $\mathrm{Na}^{+}$ channel isoform expression in Xenopus laevis oocytes, cDNA encoding rat $\mathrm{rNa}_{\mathrm{v}} 1.2$ and murine $\mathrm{mNa}_{\mathrm{v}} 1.6$ were cloned into the plasmid pLCT1, whereas the gene encoding the rat isoform $\mathrm{rNa}_{\mathrm{v}} 1.4$ was cloned into the plasmid pUI-2. For in vitro transcription these plasmids were linearized by the restriction enzyme NotI. The construct $\mathrm{h} \beta 1 / \mathrm{pGEM}-\mathrm{HE}$ containing the gene of the human $\beta 1$-subunit was linearized by the NheI enzyme. Plasmids containing cDNA of human isoform $\mathrm{hNa}_{\mathrm{v}} 1.5$, human and rat $\beta 1$-subunits (pSP64T), as well as rat $\mathrm{rNa}_{\mathrm{v}} 1.8$ (pBSTA) were linearized using XbaI, EcoRI and NotI, respectively. Plasmids encoding insect channel subunits ( $\mathrm{DmNa}_{\mathrm{v}} 1 / \mathrm{pGH} 19-13-5$ and tipE/pGH19) were linearized by NotI. Capped RNAs were synthesized from linearized plasmids using the mMESSAGE mMACHINE T7 transcription kit (Ambion, USA). $X$. laevis oocytes were harvested from the ovarian lobes of anaesthetized female frogs at the stages V-VI. Oocytes were injected with $50 \mathrm{nl}$ of RNA $(\alpha: \beta$-subunit ratio of $1: 1)$ at a concentration of $1 \mathrm{ng} / \mathrm{nl}$ using a micro-injector (Drummond Scientific, USA). The oocytes were incubated for 2-4 days in solution that contained $96 \mathrm{mM}$ $\mathrm{NaCl}, 2 \mathrm{mM} \mathrm{KCl}, 1.8 \mathrm{mM} \mathrm{CaCl}_{2}, 2 \mathrm{mM} \mathrm{MgCl}$ and $5 \mathrm{mM}$ HEPES (pH 7.4) and was supplemented with $50 \mathrm{mg} / \mathrm{l}$ gentamycin sulfate.

Active venom components were tested on the oocytes expressing genes of channel proteins using the two-electrode voltage clamp method at room temperature. Electrodes were filled with $3 \mathrm{M} \mathrm{KCl}$, the resistance was $<1 \mathrm{M} \Omega$. Recorded data was analyzed using GeneClamp 500 (Axon Instruments, USA). In this study, we used the following protocols. In order to achieve a maximum activation of channels, the oocytes membrane depolarization was induced from the holding potential of $-90 \mathrm{mV}$ to $40 \mathrm{mV}$ for $100 \mathrm{~ms}$ at a frequency of $0.2 \mathrm{~Hz}$. The inhibitory effect was registered after addition of toxin as a reduction of the current amplitude. To study the current-voltage dependence of activation, membrane depolarization was induced from $-90 \mathrm{mV}$ to $40 \mathrm{mV}$ at intervals of every $5 \mathrm{mV}$. Average $\mathrm{Na}^{+}$ion conductivity was calculated to build the activation curves; the obtained data were analyzed by the Boltzmann equation. Processing and visualization of the results was carried out using the program Origin (OriginLab, USA).

Mass spectrometry. Toxin molecular mass measurements were carried out using the method of matrixassisted laser desorption-ionization (MALDI) on a M@LDI-LR mass spectrometer (Micromass, UK) with identification of positive ions in linear mode. The 2,5dihydroxy benzoic acid $(10 \mathrm{mg} / \mathrm{ml}$ in $50 \%$ (v/v) acetonitrile, $0.1 \%$ TFA) matrix was used. Samples were prepared using the dried droplet method: equal volumes $(0.5 \mu \mathrm{l})$ of sample and matrix were mixed on the target 
plate and left to dry in the air. Calibration was performed using the ProteoMass calibration kit with molecular mass range of 700-66000 Da (Sigma, USA).

Reduction of disulfide bonds and modification of thiol groups. Dried samples were dissolved in $40 \mu \mathrm{l}$ of solution containing $6 \mathrm{M}$ guanidine hydrochloride, $3 \mathrm{mM}$ EDTA, $0.5 \mathrm{M}$ Tris-HCl (pH 8.5). Then $2 \mu \mathrm{l}$ of $1.4 \mathrm{M}$ 1,4-dithiothreitol were added and the sample was incubated overnight at $30^{\circ} \mathrm{C}$. Four $\mu \mathrm{l}$ of $50 \% 4$-vinylpyridine in isopropanol $(\mathrm{v} / \mathrm{v})$ were added to the samples, followed by the incubation for 15-20 min at room temperature in the dark. Modified polypeptides were separated by RP-HPLC column on a Jupiter $C_{5}(2 \times 150 \mathrm{~mm}$, Phenomenex, USA) using a 60-min linear gradient of acetonitrile (15-60\%) in $0.1 \%$ TFA at a flow rate of $0.3 \mathrm{ml} / \mathrm{min}$.

CNBr cleavage. One nanomole of each pure alkylated peptide was dissolved in $20 \mu \mathrm{l}$ of $80 \%$ TFA and $1 \mu \mathrm{l}$ of $5 \mathrm{M} \mathrm{CNBr}$ in acetonitrile (Sigma, USA) was added. The samples were incubated for $18 \mathrm{~h}$ at room temperature in the dark. The reaction products were separated using RP-HPLC on a Jupiter $\mathrm{C}_{5}$ column $(2 \times$ $150 \mathrm{~mm})$.

Endoproteinase Glu-C cleavage. One nmol of each purified alkylated peptide was dissolved in $20 \mu \mathrm{l}$ of $50 \mathrm{mM} \mathrm{NH}_{4} \mathrm{HCO}_{3}(\mathrm{pH} 8)$ and $0.2 \mu \mathrm{g}$ of endoproteinase Glu-C (Sigma, USA) were added. Probes were incubated for $4 \mathrm{~h}$ at $37^{\circ} \mathrm{C}$. The reaction products were separated by RP-HPLC as described in the previous section.

Protein sequencing. The N-terminal amino acid sequences of the alkylated peptides were determined on a Procise Model 492 protein/peptide sequencer (Applied Biosystems, USA) according to the manufacturer's protocol.

Homology modeling. Models of the spatial structure of the novel peptides Hm-1, 2 and 3 were built using the publicly available program MODELLER 8v1 (http://www.salilab.org/modeller) on the basis of the known structure of the spider toxin agelenin (PDB code 2E2S, http://www.rcsb.org/pdb). Accuracy of the structure was checked using the program WHAT_CHECK (http://swift.cmbi.kun.nl/gv/whatcheck) with the further minimization of the molecular potential energy by the program TINKER (http://dasher.wustl.edu/tinker) in the force field CHARMM27.

\section{RESULTS AND DISCUSSION}

At the modern stage of the development of molecular-biological and physical-chemical methods, it becomes possible to identify and characterize active components from complex mixtures provided with very limited amounts of biological material. For example, representatives of spider families such as Thomisidae are characterized by a very small size (less than $10 \mathrm{~mm}$ ) and, accordingly, we can expect only a few $\mu l$ of their venom. With substances in orders of magnitude less than decades ago, we can not only assess the composition of the whole venom and perform preliminary tests on a variety of targets, but also run a detailed characterization of the active molecules. An in-depth study of the new substance mechanism of action can be performed on specific targets, for example, using a heterological gene expression system. With shortage of natural material or even its complete absence, genetic engineering approaches can help obtain polypeptide molecules in sufficient quantities for research. Such an approach is essential to investigate the peptide structure (computer modeling is an alternative) and identify functionally important residues. This work is an example of how, with modern equipment and well-planned strategy, search and detailed study of new molecules that act on voltagegated $\mathrm{Na}^{+}$channels can be performed, operating with small quantities of the source material.

Object selection. At the first stage of this work, we tested venoms from 16 spider species belonging to nine different families ${ }^{2}$ for inhibitory activity on voltagegated $\mathrm{Na}^{+}$channels. Three isoforms of $\mathrm{Na}^{+}$channels were used as targets: TTX-S Na $1.2, \mathrm{Na}_{\mathrm{v}} 1.7$ and TTX$\mathrm{R} \mathrm{Na}_{\mathrm{v}} 1.5$; their genes were expressed in $X$. laevis oocytes. Test results are given in the table. It was found that the venoms of two spiders $H$. melloteei and Misumena vatia belonging to the family Thomisidae produce the most pronounced blocking effect. For further studies, the venom from the spider $H$. mellotee $i$ was selected as the most active.

Identification of the active components. Since insects are the natural prey of spiders, we estimated the insecticidal activity of the crude venom of $H$. mellotee $i$. It was shown that the venom at doses of $\geq 15 \mathrm{mg} / \mathrm{kg}$ caused an immediate paralysis and death of the flesh fly (S. carnaria) larvae. The value of the minimal effective dose indicated presence of components highly toxic to insects. Quite often venom toxicity is based on components active on $\mathrm{Na}^{+}$channels, such as in the case of dangerous to humans Brazilian "wandering" spiders of the genus Phoneutria and Australian "funnel-web" spiders of the genera Atrax and Hadronyche [28, 29].

With the aim of purification of active molecules, the strategy of venom multi-step HPLC separation was suggested (Fig. 1). All the fractions collected during the separation were tested for the presence of the required activity. Figure 1a shows the first stage of venom separation. Blocking activity towards mammalian $\mathrm{Na}^{+}$ channels (isoforms $\mathrm{Na}_{\mathrm{v}} 1.2$ and $\mathrm{Na}_{\mathrm{v}} 1.5$ ) was found in fractions 3-6, whereas fractions $2-6$ possessed insecticidal activity. Thus, the activity profiles overlap, which may be related to the effect of the same compounds. According to the MALDI mass-spectrometry, active fractions contained components with molecular masses in the range of 3-10 $\mathrm{kDa}$, which corresponds to the most frequently encountered masses of spider venom

${ }^{2}$ Classified by A. Feodorov (Fauna Labs; Almaty, Kazakhstan). 
Crude spider venom activity tests

\begin{tabular}{|c|c|c|c|c|}
\hline Families & Species & $\mathrm{Na}_{\mathrm{v}} 1.2$ & $\mathrm{Na}_{\mathrm{v}} 1.5$ & $\mathrm{Na}_{\mathrm{v}} 1.7$ \\
\hline Agelenidae & Agelena orientalis & 9 & 3 & 9 \\
\hline \multirow[t]{2}{*}{ Eresidae } & Eresus sp. & - & 34 & 17 \\
\hline & Stegodyphus sp. & 26 & 52 & - \\
\hline Gnaphosidae & Drassodes sp. & 33 & 71 & 35 \\
\hline \multirow[t]{6}{*}{ Lycosidae } & Alopecosa sp. & $\dagger$ & $\dagger$ & $\dagger$ \\
\hline & Desertosa sp. & $\dagger$ & $\dagger$ & $\dagger$ \\
\hline & Geolycosa sp. & $\dagger$ & $\dagger$ & $\dagger$ \\
\hline & Hippocosa sp. & $\dagger$ & $\dagger$ & $\dagger$ \\
\hline & Lycosa singoriensis & $\dagger$ & $\dagger$ & $\dagger$ \\
\hline & Nenilinia sp. & $\dagger$ & $\dagger$ & $\dagger$ \\
\hline Miturgidae & Cheiracanthium punctorium & $\dagger$ & $\dagger$ & $\dagger$ \\
\hline Philodromidae & Tibellus oblongus & 47 & 53 & 9 \\
\hline Theridiidae & Latrodectus dahli & 6 & 36 & 8 \\
\hline \multirow[t]{2}{*}{ Thomisidae } & Heriaeus melloteei & 87 & 81 & 80 \\
\hline & Misumena vatia & 69 & 36 & 100 \\
\hline Zodariidae & Lachesana tarabaevi & $\dagger$ & $\dagger$ & $\dagger$ \\
\hline
\end{tabular}

Note: The values represent the percent of $\mathrm{Na}^{+}$current amplitude decrease in various isoforms at a venom concentration of $0.1 \mathrm{mg} / \mathrm{ml}$. - , not tested; $\dagger$, oocyte lysis.

peptides. Fractions 3, 5 and 6 have been selected for further investigation; we also plan to study the active components of fractions 2 and 4 in the future. As a result of two additional stages of HPLC, $\mathrm{Na}^{+}$channel blockers named Hm-1, 2 and 3 were purified to homogeneity (Fig. 1). Purity of the isolated compounds was confirmed by analytical HPLC and MALDI mass-spectrometry. The measured average molecular masses of the toxins are 4171.9 $\mathrm{Da}(\mathrm{Hm}-1), 4555.3 \mathrm{Da}(\mathrm{Hm}-2)$ and 3907.7 Da (Hm-3).

Structure of the new blockers. Full amino acid sequences of the new $\mathrm{Na}^{+}$channel blockers (Fig. 2) were established by a combination of automated Edman degradation, selective cleavage of polypeptide chains at methionine (with $\mathrm{CNBr}$ ) and glutamic acid residues (with endoproteinase Glu-C) and mass-spectrometry. Because of the difference of measured molecular masses and the corresponding calculated values based on the sequence $(\Delta=1 \mathrm{Da})$, we concluded that toxin $\mathrm{Hm}-1$ carries a posttranslational modification, namely, C-terminal amidation. All new peptides contain six cysteine residues forming three intramolecular $\mathrm{S}-\mathrm{S}$ bridges. Location of cysteine residues in the amino acid sequences suggests the formation of the "cystine knot" spatial motif characteristic of many other spider peptide toxins. For Hm-2 and 3, no similar sequences were found in the UniProt database (http://www.uniprot.org), but they showed some degree of similarity between each other ( $46 \%$ identical residues). Hm-1 sequence showed a low degree of similarity with the known peptides agelenin (UniProt code P31328) and $\mu$ agatoxin-2 (P11058) isolated from spider venoms and active on voltage-gated $\mathrm{Ca}^{2+}-$ and $\mathrm{Na}^{+}$channels, respectively (Fig. 3).

The spatial structure of the isolated molecules is not yet established. However, with the help of computer modeling it is possible to build their model structures on the basis of similarities with the toxins for which the $3 \mathrm{D}$ structure has already been resolved. Figure 4 presents the results of homology modeling of Hm-1, 2 and 3 on the template structure of agelenin, a toxin acting on $\mathrm{Ca}^{2+}$ channels that has the most similar amino acid sequence to the newly described peptides and is characterized by the "cystine knot" fold [30]. In the future we plan to identify amino acid residues responsible for interaction with the channel protein, and their spatial location on the models will indicate the possible pharmacophore.

Functional characterization. Application of all studied compounds at concentrations $\sim 100 \mathrm{nM}^{\circ} \mathrm{Na}^{+}$ channels decrease the amplitude of the $\mathrm{Na}^{+}$current (Figs. 5, 6). In the case of Hm-1 and 2, no changes in 

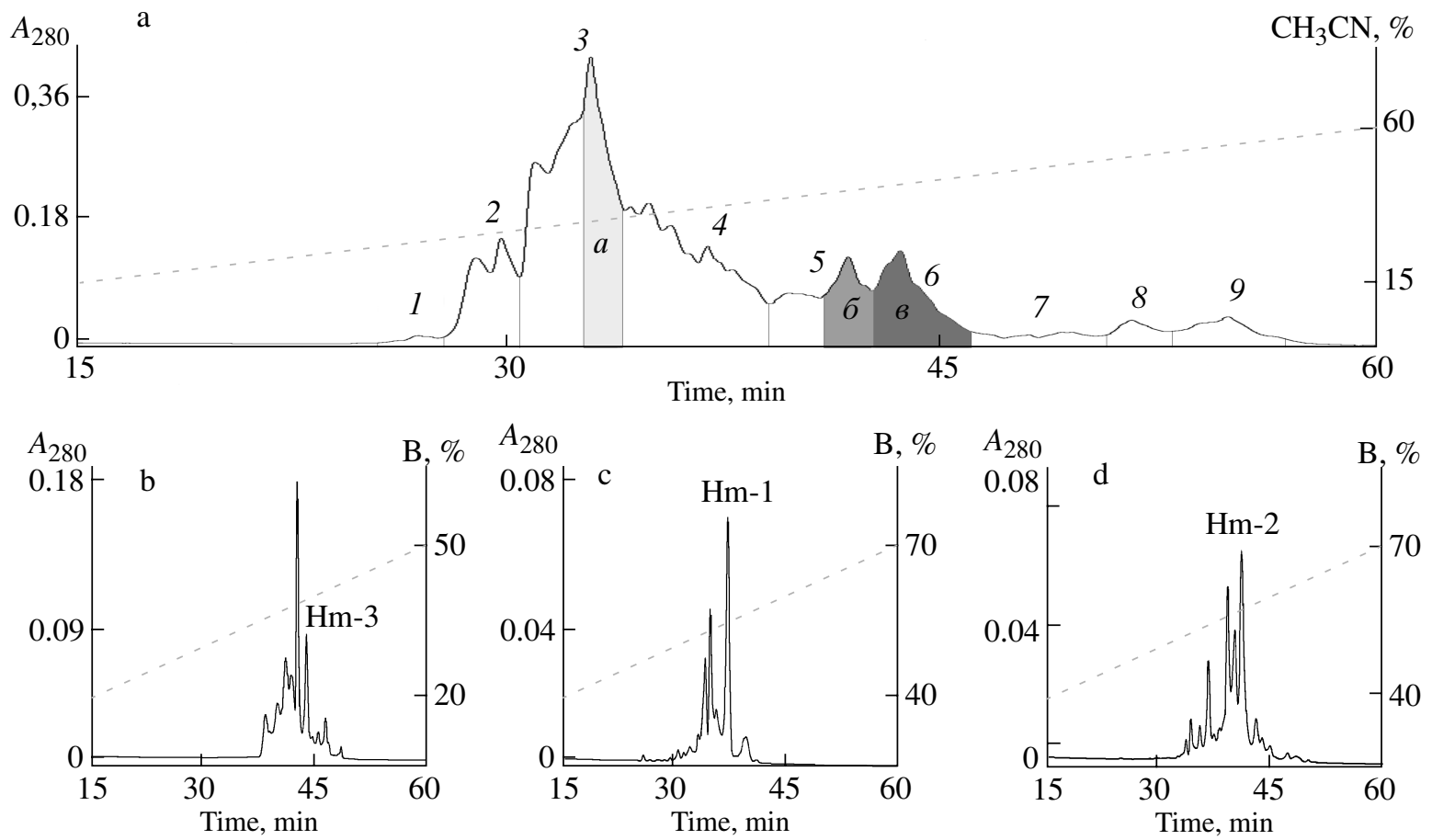

Fig. 1. Isolation of $\mathrm{Na}^{+}$channel blockers from the venom of $H$. melloteei. (a) Separation of $20 \mu \mathrm{l}$ of crude venom by RP-HPLC on a Jupiter $\mathrm{C}_{5}(4.6 \times 150 \mathrm{~mm})$ column using a 60 -min linear gradient of acetonitrile (indicated with a line) at a flow rate of $1 \mathrm{ml} / \mathrm{min}$. Numbers indicate fractions tested for insecticidal activity. The second step of separation of the active fractions $a$ (b), $b$ (c), and $c$ (d) on a Luna $\mathrm{C}_{8}(4.6 \times 150$ III) column using a linear gradient of solvent $\mathrm{B}$ (50\% acetonitrile, $20 \%$ isopropanol; marked by line) at a flow rate of $1 \mathrm{ml} / \mathrm{min}$. The active fractions are indicated as $\mathrm{Hm}-1, \mathrm{Hm}-2$ and $\mathrm{Hm}-3$.

the current-voltage relationships of the channels, as well as the kinetics of activation and inactivation occur (Fig. 6) [27]. Thus, the mode of action of these toxins appears to be pore-blocking. For all the new molecules no significant specificity of action with respect to isoforms of mammalian $\mathrm{Na}^{+}$channels was found. Figure 5 shows recordings of $\mathrm{Na}^{+}$currents modified by applica- tions of the toxin $\mathrm{Hm}-2$. It is seen that this peptide is most active on the insect channels, as well as mammalian TTX-S $\mathrm{Na}_{\mathrm{v}} 1.2$ and $\mathrm{Na}_{\mathrm{v}} 1.4$, and least active on the TTX-R $\mathrm{Na}_{\mathrm{v}} 1.5$ and $\mathrm{Na}_{\mathrm{v}} 1.8$. For the muscle-type channel (isoform $\mathrm{Na}_{\mathrm{v}} 1.4$ ), the dose-response curves were obtained, and the effective concentrations causing a $50 \%$ reduction in the amplitude of $\mathrm{Na}^{+}$current were

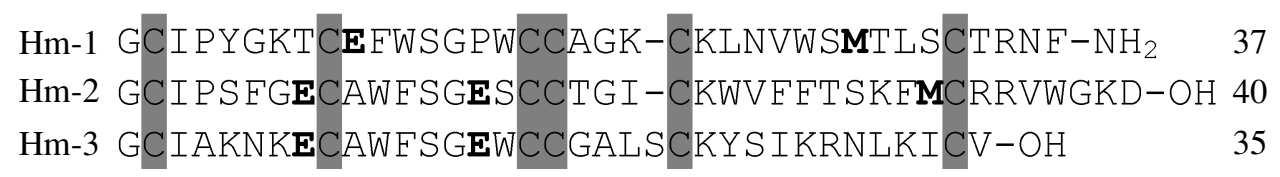

Fig. 2. Amino acid sequences of the isolated $\mathrm{Na}^{+}$channel blockers. Methionine and glutamic acid residues are in bold, cysteine residues are shaded grey. The number of amino acid residues in the polypeptide chain of the corresponding toxin is indicated in the right column. Gaps were introduced to optimize the sequences comparison.

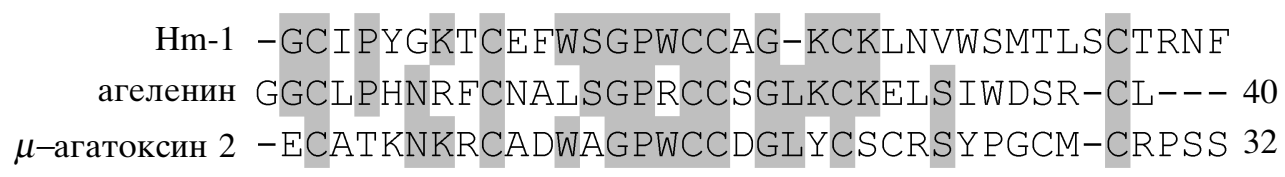

Fig. 3. Hm-1 amino acid sequence comparison with other known peptides. Identical residues are shaded grey. The percent of identical amino acid residues with $\mathrm{Hm}-1$ is indicated in the right column. 

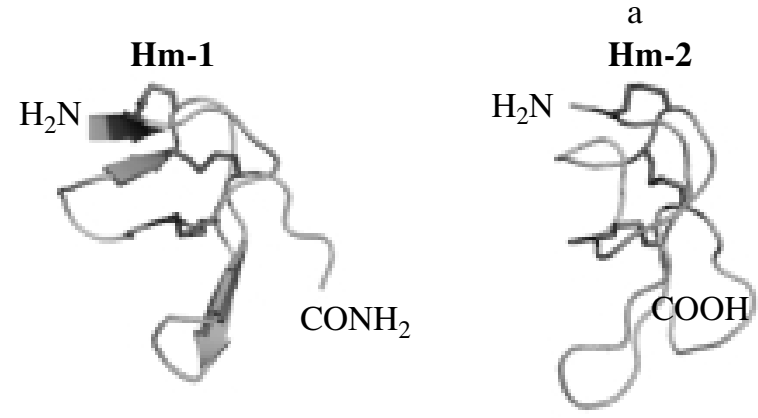

$\mathrm{b}$

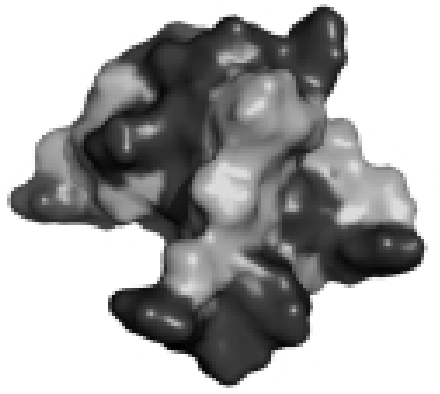

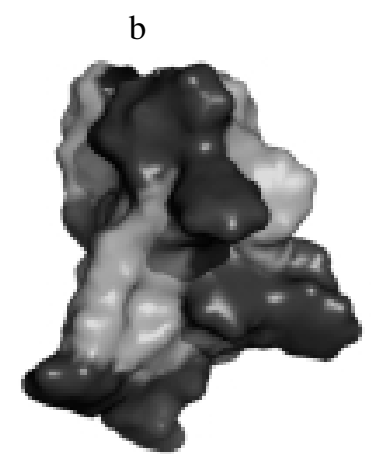
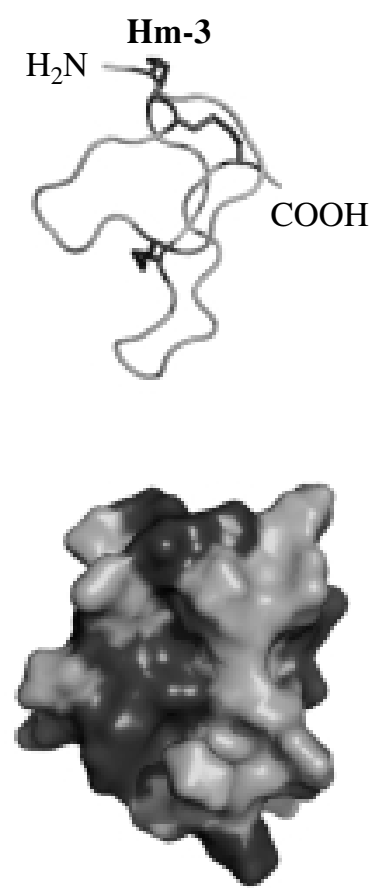

Fig. 4. Spatial model structures of Hm-1, 2 and 3. (a) Ribbon models. Cysteine residues and disulfide bonds are marked dark grey. $\mathrm{N}$ - and C- termini are indicated. (b) Space-filling models. Hydrophobic residues are marked dark gray and hydrophilic ones, light gray.

identified, which amounted to $\sim 350 \mathrm{nM}$ and $\sim 160 \mathrm{nM}$ in case of Hm-1 and 2, respectively [27].

Values of the effective concentrations for the described peptides are sufficiently high in comparison with some other toxins but the uniqueness of $\mathrm{Hm}-1$ and 2 is that, unlike the vast majority of polypeptide ligands of $\mathrm{Na}^{+}$channels, they appear to be typical pore blockers. This feature brings them together with TTX and saxitoxin, and therefore they are expected to interact with the same parts of the channel, i.e., receptor site 1. $\mathrm{Hm}-3$, despite considerable similarity in amino acid sequence with Hm-2 (46\% identical residues), has a different mechanism of action. In Fig. 6, a distinct shift in current-voltage relationship of the channel under the action of Hm-3 is noticeable, whereas such an effect is absent in the case of $\mathrm{Hm}-1$ and 2. Similar mode of action was found for some other spider toxins: JZTXIII from the spider Chilobrachys jingzhao and ProTxI and II from the spider Thrixopelma pruriens that bind to receptor site $4[31,32]$. We assume that $\mathrm{Hm}-3$ also interacts with site 4 . It should be noted that the classical $\mathrm{Na}^{+}$channel modulators acting on site 4 are the scorpion $\beta$-toxins. The mode of their action, however, is different: the activation process is not inhibited but instead potentiated, the threshold potential is shifted to the more negative values [33]. The same effects are seen with $\mu$-agatoxins from the spider Agelenopsis aperta and Magi 5 from the spider Macrothele gigas [34, 35]. $\delta$-Palutoxins from the spider Paracoelotes luctuosus interact with site 4 , but the physiological effects are similar to those of scorpion $\alpha$-toxins [36]. Thus, there is a wide variety in pharmacological activity of $\mathrm{Na}^{+}$ channel peptide modulators. Peptides that interact with common sites of the channel protein can have different effects on its activity and conversely, peptides that interact with different receptor sites may produce similar physiological effects.

\section{CONCLUSIONS}

As a result of this work, we have described three polypeptide molecules from the venom of the spider H. melloteei that act on $\mathrm{Na}^{+}$channels. The low degree of similarity with other known peptides suggests that these substances belong to new groups of $\mathrm{Na}^{+}$channel blockers. In doing so, Hm-1 and 2, it seems, are pore blockers and are associated with receptor site 1 , and Hm-3 interferes with channel activation and is likely to interact with receptor site 4 . Molecules described in this paper represent new tools for studying the structure and function of $\mathrm{Na}^{+}$channels.

\section{ACKNOWLEDGEMENTS}

We are grateful to A.L. Goldin (University of California, Irvine, USA), G. Mandel (Stony Brook University, Stony Brook, USA), R.G. Kallen (University of Pennsylvania, Philadelphia, USA), J.N. Wood (University College, London, UK), S.H. Heinemann 

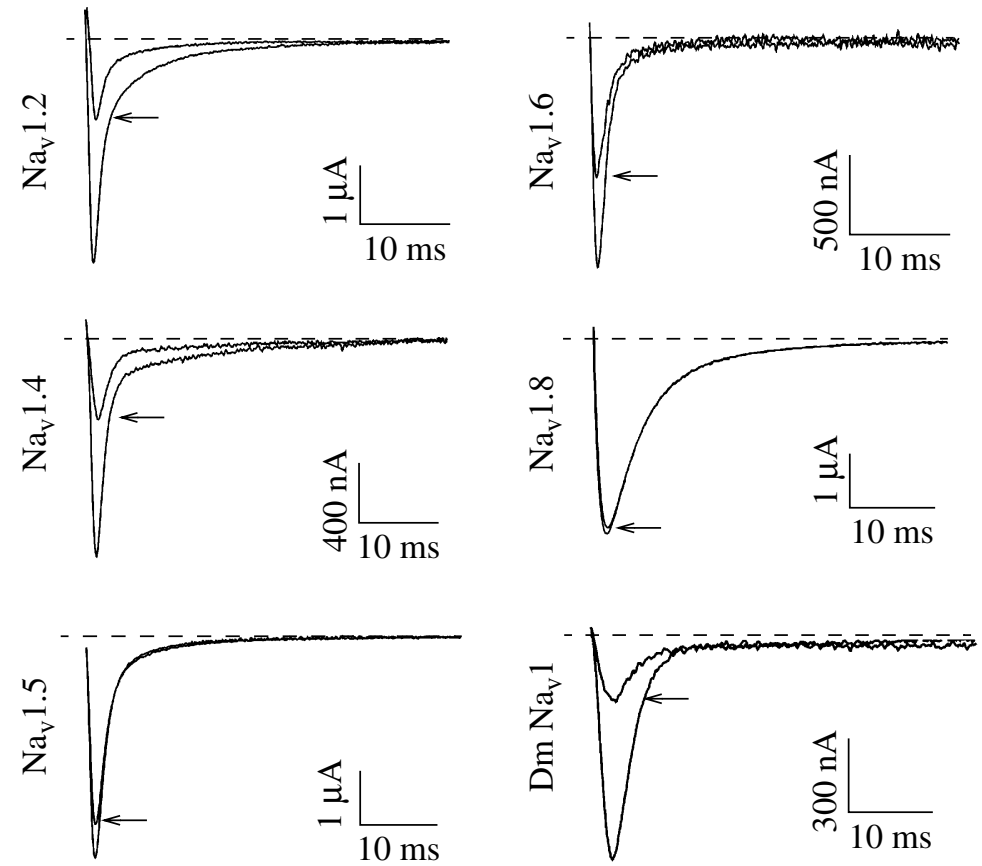

Fig. 5. Effects of $\mathrm{Hm}-2$ on different $\mathrm{Na}^{+}$channel isoforms: $\mathrm{Na}_{\mathrm{v}} 1.2,1.4,1.5,1.8$ and $\mathrm{DmNa}_{\mathrm{v}} 1$ expressed in Xenopus oocytes. The arrow indicates the $\mathrm{Na}^{+}$current peak amplitude in the presence of $200 \mathrm{nM}$ of toxin.
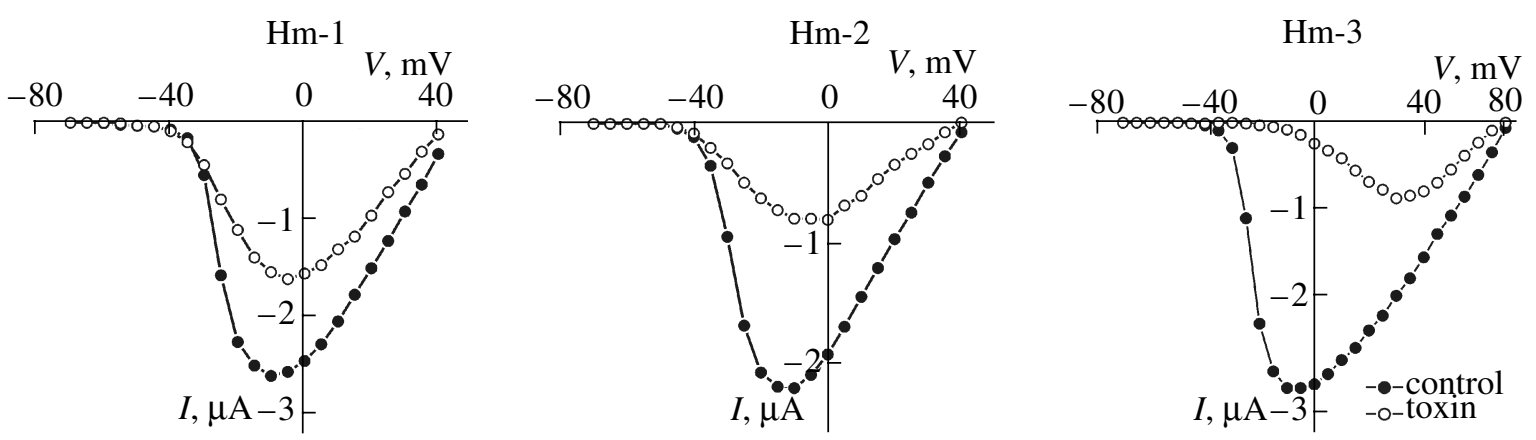

Fig. 6. Current-voltage relationships of $\mathrm{Na}^{+}$channel muscle isoform $\left(\mathrm{Na}_{\mathrm{v}} 1.4\right)$ in the presence of toxins. Filled circles (@), control; open circles (@), toxin applications. Concentrations of toxins: Hm-1, $200 \mathrm{nM} ; \mathrm{Hm}-2,200 \mathrm{nM} ; \mathrm{Hm}-3,1 \mu \mathrm{M}$.

(Friedrich-Schiller-Universität, Jena, Germany), and S.C. Cannon (University of Texas, Dallas, USA), M.S. Williamson (IACR-Rothamsted, UK) for sharing plasmids with genes encoding $\mathrm{Na}^{+}$channels. We also thank S. Debaveye for her technical assistance in molecular biology.

The work was supported by the Russian Foundation for Basic Research, the Program of Cell and Molecular Biology of Russian Academy of Sciences, BIL05/50 (Bilateral collaboration between Flanders and the Russian Federation), G.0257.08 (F.W.O. Vlaanderen), OT05-64 (K.U. Leuven), UA P6/31 (Interuniversity Attraction Poles Program - Belgian State - Belgian Science Policy).

\section{REFERENCES}

1. Catterall, W.A., From Ionic Currents to Molecular Mechanisms: The Structure and Function of VoltageGated Sodium Channels, Neuron, 2000, vol. 26 (1), pp. 13-25.

2. Mozhaeva, G.N., Naumov, A.P., and Khodorov, B.I., Activation and Inactivation of Batrachotoxin-Modified Sodium Channels of Nerve Fiber Membranes in the Frog, Neirofiziologiia (Rus.), 1984, vol. 16 (1), 1 pp. 18-26.

3. Mozhaeva, G.N., Naumov, A.P., and Nosyreva, E.D., Features of the Kinetic and Stationary Characteristics of Aconitine-Modified Sodium Channels, Neirofiziologiia 1 (Rus.), 1980, vol. 12 (6), pp. 612-618.

4. Mozhaeva G.N., Naumov, A.P., and Neguliaev, Iu.A., The Influence of Aconitine on Several Properties of the 
Sodium Channels of the Membranes of Nodes of Ranvier, Neirofiziologiia (Rus.), 1976, vol. 8. (2), pp.152-160.

5. Mozhaeva, G.N. and Naumov, A.P., Kinetics of the Reaction between Scorpion Toxin and the Sodium Channels of Nodes of Ranvier, Neirofiziologiia (Rus.), 1980, vol. 12 (6), pp. 619-626.

6. Mozhaeva, G.N., Naumov, A.P., and Nosyreva, E.D., Kinetics of Sodium Current Decay during Normal Axon Membrane Repolarization and in the Presence of Scorpion Toxin, Neirofiziologiia (Rus.), 1980, vol. 12. (5), pp. 541-549.

7. Mozhaeva, G.N., Naumov, A.P., Soldatov, N.M., and Grishin, E.V., Effect of Toxins from the Scorpion Buthus eupeus on the Sodium Channels of the Membranes of Nodes of Ranvier, Biofizika (Rus.), 1979, vol. 24. (2), pp. 235-241.

8. Grishin, E., Polypeptide Neurotoxins from Spider Venoms, Eur. J. Biochem., 1999, vol. 264 (2), pp. 276-280.

9. Corzo, G. and Escoubas, P., Pharmacologically Active Spider Peptide Toxins, Cell. Mol. Life Sci., 2003,vol. 60 (11), pp. 2409-2426.

10. Honma, T. and Shiomi, K., Peptide Toxins in Sea Anemones: Structural and Functional Aspects, Mar. Biotechnol., 2006, vol. 8 (1), pp. 1-10.

11. Rodriguez de la Vega, R.C. and Possani, L.D., Overview of Scorpion Toxins Specific for $\mathrm{Na}_{+}$Channels and Related Peptides: Biodiversity, Structure-Function Relationships and Evolution, Toxicon, 2005, vol. 46 (8), pp. 831-844.

12. Terlau, H. and Olivera, B.M., Conus Venoms: A Rich Source of Novel Ion Channel-Targeted Peptides, Physiol. Rev., 2004, vol. 84 (1), pp. 41-68.

13. Yu, F.H. and Catterall, W.A., Overview of the VoltageGated Sodium Channel Family, Genome Biol., 2003, vol. 4 (3), p. 207.

14. Catterall, W.A., Structural Biology: A 3D View of Sodium Channels, Nature, 2001, vol. 409, pp. 988-991.

15. Catterall, W.A., Goldin, A.L., and Waxman, S.G., International Union of Pharmacology. XLVII. Nomenclature and Structure-Function Relationships of Voltage-Gated Sodium Channels, Pharmacol. Rev., 2005, vol. 57 (4), pp. 397-409.

16. Cestele, S. and Catterall, W.A., Molecular Mechanisms of Neurotoxin Action on Voltage-Gated Sodium Channels, Biochimie, 2000, vol. 82 (9-10), pp. 883-892.

17. Billen, B., Bosmans, F., and Tytgat, J., Animal Peptides Targeting Voltage-Activated Sodium Channels, Curr. Pharm. Des., 2008, vol. 14(24), pp. 2492-2502.

18. Wang, S.Y. and Wang, G.K., Voltage-Gated Sodium Channels As Primary Targets of Diverse Lipid-Soluble Neurotoxins, Cell Signal, 2003, vol.15 (2), pp. 151-159.

19. Li, D., Xiao, Y., Hu, W., Xie, J., Bosmans, F., Tytgat, J., and Liang, S., Function and Solution Structure of Hainantoxin-I, a Novel Insect Sodium Channel Inhibitor from the Chinese Bird Spider Selenocosmia hainana, FEBS Lett., 2003, vol. 555 (3), pp. 616-622.

20. Xiao, Y. and Liang, S., Inhibition of Neuronal Tetrodotoxin-Sensitive $\mathrm{Na}^{+}$Channels by Two Spider Toxins: Hainantoxin-III and Hainantoxin- IV, Eur. J. Pharmacol., 2003, vol. 477 (1), pp. 1-7.
21. Xiao, Y.C. and Liang, S.P., Purification and Characterization of Hainantoxin-V, a Tetrodotoxin-Sensitive Sodium Channel Inhibitor from the Venom of the Spider Selenocosmia hainana, Toxicon, 2003, vol. 41 (6), pp. 643-650.

22. Peng, K., Shu, Q., Liu, Z., and Liang, S., Function and Solution Structure of Huwentoxin-IV, a Potent Neuronal Tetrodotoxin (TTX)-Sensitive Sodium Channel Antagonist from Chinese Bird Spider Selenocosmia huwena, J. Biol. Chem., 2002, vol. 277 (49), pp. 47564-47571.

23. Wang, M., Guan, X., and Liang, S., The Cross Channel Activities of Spider Neurotoxin Huwentoxin-I on Rat Dorsal Root Ganglion Neurons, Biochem. Biophys. Res. Commun., 2007, vol. 357 (3), pp. 579-583.

24. Xiao, Y., Luo, X., Kuang, F., Deng, M., Wang, M., Zeng, X., and Liang, S., Synthesis and Characterization of Huwentoxin-IV, a Neurotoxin Inhibiting Central Neuronal Sodium Channels, Toxicon, 2008, vol. 51 (2), pp. 230-239.

25. Diniz, M.R., Theakston, R.D., Crampton, J.M., Nascimento Cordeiro, M., Pimenta, A.M., De Lima, M.E., and Diniz, C.R., Functional Expression and Purification of Recombinant Tx1, a Sodium Channel Blocker Neurotoxin from the Venom of the Brazilian "Armed" Spider, Phoneutria nigriventer, Protein Expr. Purif., 2006, vol. 50 (1), pp. 18-24.

26. Martin-Moutot, N., Mansuelle, P., Alcaraz, G., Dos Santos, R.G., Cordeiro, M.N., De Lima, M.E., Seagar, M., and van Renterghem, C., Phoneutria nigriventer Toxin 1: A Novel, State-Dependent Inhibitor of Neuronal Sodium Channels That Interacts with Micro Conotoxin Binding Sites, Mol. Pharmacol., 2006, vol. 69 (6), pp. 1931-1937.

27. Billen, B., Vassilevski, A., Nikolsky, A., Tytgat, J., and Grishin, E., Two Novel Sodium Channel Inhibitors from Heriaeus melloteei Spider Venom Differentially Interacting with Mammalian Channel's Isoforms, Toxicon, 2008, vol. 52, pp. 309-317.

28. Gomez, M.V, Kalapothakis, E., Guatimosim, C., and Prado, M.A., Phoneutria nigriventer Venom: A Cocktail of Toxins That Affect Ion Channels, Cell. Mol. Neurobiol., 2002, vol.22 (5-6), pp. 579-588.

29. Nicholson, G.M, Little, M.J, Tyler, M., and Narahashi, T., Selective Alteration of Sodium Channel Gating by Australian Funnel-Web Spider Toxins, Toxicon, 1996, vol. 34(11-12), pp. 1443-1453.

30. Yamaji, N., Sugase, K., Nakajima, T., Miki, T., Wakamori, M., Mori, Y., and Iwashita, T., Solution Structure of Agelenin, an Insecticidal Peptide Isolated from the Spider Agelena opulenta, and Its Structural Similarities to Insect-Specific Calcium Channel Inhibitors, FEBS Lett., 2007, vol. 581(20), pp. 3789-3794.

31. Xiao, Y., Tang, J., Yang, Y., Wang, M., Hu, W., Xie, J., Zeng, X., and Liang, S., Jingzhaotoxin-III, a Novel Spider Toxin Inhibiting Activation of Voltage-Gated Sodium Channel in Rat Cardiac Myocytes, J. Biol. Chem., 2004, vol. 279 (25), pp. 26220-26226.

32. Priest, B., Blumenthal, K., Smith, J., Warren, V., and Smith, M., ProTx-I and ProTx-II: Gating Modifiers of Voltage-Gated Sodium Channels, Toxicon, 2007, vol. 49 (2), pp. 194-201. 
33. Cest?le, S., Qu, Y., Rogers, J.C., Rochat, H., Scheuer, T., and Catterall, W.A., Voltage Sensor-Trapping: Enhanced Activation of Sodium Channels by Beta-Scorpion Toxin Bound to the S3-S4 Loop in Domain II, Neuron, 1998, vol. 21 (4), pp. 919-931.

34. Skinner, W.S., Adams, M.E., Quistad, G.B., Kataoka, H., Cesarin, B.J., Enderlin, F.E., and Schooley, D.A., Purification and Characterization of Two Classes of Neurotoxins from the Funnel Web Spider, Agelenopsis aperta, J. Biol. Chem., 1989, vol. 264 (4), pp. 2150-2155.
35. Corzo, G., Gilles,N., Satake, H., Villegas, E., Dai, L., Nakajima, T., and Haupt, J., Distinct Primary Structures of the Major Peptide Toxins from the Venom of the Spider Macrothele gigas That Bind to Sites 3 and 4 in the Sodium Channel, FEBS Lett., 2003, vol. 547 (1-3), pp. $43-50$.

36. Corzo, G., Escoubas, P., Villegas, E., Karbat, I., Gordon, D., Gurevitz, M.,Nakajima, T., and Gilles, N., A Spider Toxin That Induces a Typical Effect of Scorpion $\alpha$-Toxins but Competes with ?-Toxins on Binding to Insect Sodium Channels, Biochemistry, 2005, vol. 44 (5), pp. 1542-1549.

SPELL: 1. Neirofiziologiia 